\title{
Yol Yüzey Anormalisinin Tespiti ve Analizi
}

\author{
Erkan DEVECİ*, Burhan ERGEN \\ Fırat Üniversitesi, Mühendislik Fakültesi, Bilgisayar Mühendisliği Bölümü, Elazı̆̆ \\ (ORCID: 0000-0002-3985-4156) (ORCID: 0000-0003-3244-2615)
}

\begin{abstract}
$\ddot{\mathbf{O z}}$
Kentleşmenin şehirlerin hızlı gelişmesine neden olması gelişen şehirlerin alt yapılarının takibi ve güncellenme gerekliliğinin analizini zorunlu kılmıştır. Özellikle ulaşım karmaşasının önüne geçmek için çeşitli trafik planlamaları yapmanın yanı sıra ulaşımın sağlandığı kara yolunun niteliğinin de yeterli seviyede olması gereklidir. Yolun yapısal kusurların ve çatlaklarının manuel görsel muayenesi verinin hacmi ve yapının boyutu nedeniyle çok zaman alan zahmetli bir süreçtir. Yoldaki çatlakların ve kusurların manuel olarak incelenmesi, yorgunluk, sorumsuz denetim, zayıf göz görme gibi bir dizi nedenlerden dolayı insan hatası nedeniyle yeterli seviyede değerlendirilememektedir. Yol kusurlarının belirlenmesi, sürücüler için önemli olmakla beraber yaya gibi tüm yol kullanıcılarının güvenliği ve konforunu sağlamak için çukurlar, hız tümsekleri vb. yol yüzeyi anormalliklerinin izlenmesi büyük önem taşımaktadır. Bu çalışmada yol yüzey kalitesinin izlenmesine ve sürücülere daha güvenli bir yol sunmak adına kullanışlı bir otomatik algılama sisteminin geliştirilmesine odaklanmaktadır. Veri seti kamera sayesinde alınan verilerle oluşturulmuştur. Verilerin önişleme fazı tamamlandıktan sonra VGG-16 mimarisi kullanılarak sonuçlar alınmış, kazanç ve kayıp grafikleri çizdirilmiş ve tahminler yapılmıştır. Öncelikle veri setimiz 1 Bloklu VGG-16 Mimarisi’ ne uygulanmış ve \%83,988 oranında doğruluğa ulaşılmıştır. Daha sonra veri seti 2 Bloklu VGG-16 Mimarisi'nden geçerek \%93,895 oranında başarıya ulaşmıştır. Son olarak veri setimize 3 Bloklu VGG-16 Mimarisi uygulanmış ve 1 Bloklu VGG-16 ve 2 Bloklu VGG-16'ya nazaran en yüksek başarı oranı olan \%95,930 ve en düșük hata oranı ile \%0,1'in altına inmiștir. Modelin başarısını artırmak için eğer bellek boyutumuz kısıtlı değilse kullanılan veri setinin kapsamını genişletmek ya da 4 Bloklu VGG-16 modeli için sonuçlar alınmalıdır.
\end{abstract}

Anahtar kelimeler: Derin Öğrenme, Karayolu Anormalisi, Yol Çatlă̆1.

\section{Detection and Analysis of Road Surface Anomaly}

\begin{abstract}
The rapid development of cities due to urbanization has made it necessary to follow up the infrastructure of developing cities and analyze the necessity of updating. Especially in order to prevent transportation complexity, besides making various traffic plans, the quality of the road on which the transportation is provided should be at a sufficient level. Manual visual inspection of road structural defects and cracks is a time-consuming and laborious process due to the volume of data and the size of the structure. Manual inspection of cracks and defects on the road cannot be adequately assessed due to human error due to a number of reasons such as fatigue, irresponsible inspection, poor eye vision. Identification of road defects is important for drivers, but potholes, speed bumps, etc. to ensure the safety and comfort of all road users such as pedestrians. Monitoring road surface anomalies is of great importance. This study focuses on the monitoring of road surface quality and the development of a useful automatic detection system to provide drivers with a safer route. The data set was created with the data received by the camera. After the preprocessing phase of the data was completed, results were obtained using VGG-16, gain and loss graphs were plotted and predictions were made. First of all, our data set was applied to 1-Block VGG-16 Architecture and \%83.988 accuracy was achieved. Later, the data set passed the 2Block VGG-16 Architecture and achieved a success rate of \%93,895. Finally, 3-Block VGG-16 Architecture was applied to our dataset and compared to 1-Block VGG-16 and 2-Block VGG-16, the highest success rate was \%95,930 and the lowest error rate was below $0.1 \%$. In order to increase the success of the model, if our memory size is not limited, results should be taken to expand the scope of the data set used or for the 4-Block VGG-16 model.
\end{abstract}

Keywords: Deep Learning, Highway Anomaly, Road Crack.

*Sorumlu yazar: erkandeveciceng@gmail.com

Geliş Tarihi: 30.04.2021, Kabul Tarihi: 05.07.2021 


\section{Giriş}

Yol çatlağı tespiti, karayolu tehlike değerlendirmesi alanında önemli bir rol oynar. Yoldaki anormallikleri ve çatlakları tespit etmek için son yıllarda birçok çalışma yapılmıştır [1]. Geleneksel çatlak tespit yöntemleri esas olarak manuel çalışmaya dayanır. Günümüzde, tamamen insan deneyimineve değerlendirmesine dayalı zaman alıcı ve zahmetli bir çalışmadır.

$\mathrm{Bu}$ nedenle, yoldaki çatlakları hızlı ve doğru bir şekilde tespit etmek ve tanımlamak için otomatik çatlak tespiti çok önemlidir [2]. Bu prosedür, sürekli yol durumu incelemelerinin gerekli olduğu durumlarda yol kalitesinin iyileştirmesine yardımcı olmak ve değerlendirmek için akıllı bakım sistemlerinin önemli bir parçasıdır. Son on yılda, yüksek hızlı mobil kameraların ve büyük kapasiteli donanım depolama cihazlarının geliştirilmesi, büyük ölçekli yol görüntüleri elde etmeyi kolaylaştırmıştır. Araç üzerineyerleştirilecek duyarga ve kamera donanımları ile karayolu gibi çevresel yapıyı izlemek ve koordinat olarak haritada bulunulan yeri belirlemek mümkün olabilmektedir. Depolanabilecek görüntülerin işlenmesi ile yol yüzeyinin analizinin yapılması mümkündür [3]. Günümüzde, toplanan çatlak görüntülerini işlemek ve ardından nihai bakım değerlendirme sonuçlarını elde etmek için bilgisayarla görme algoritmaları kullanılmaktadır [4].

Aracın seyri esnasında araca yerleştirilen kamera ile de yol yüzeyinde bulunan çatlakların görüntüleri alınmakta ve imge veri tabanına kaydedilmektedir. Bu imge verileri ile imge analizi, gürültü tespiti, şiddete göre derecelendirme işlemi yapılabilmekte ve yol yüzeyinde olan anormallikler tespit edilmektedir. Bu sayede daha sonra kişisel olarak ya da kurumlar tarafindan kullanılabilecek bilgilerin elde edilmesi mümkündür. Genel olarak, yol yüzeylerinde ortaya çıkan ilk sıkıntıçatlaklardır ve çatlakların yayılmasını veya oluşmasını önlemek için uygun izleme ve bakım önemlidir. Yol kaplamalarındaki çatlakları belirlemeye yönelik gelenekselyöntemler son derece zaman alıcı ve yüksek maliyetlidir. Çoğu çatlak özelliklerini tanımlamak karmaşık topolojik yapılar, zayıf süreklilik ve imgedeki düşük kontrast nedeniylezorluklar içermektedir. Bu nedenle, otomatik çatlak algılama yöntemleri üzerine çalışmalar devam etmektedir. Araçlardabulunan kameralar ile toplanan görüntüler üzerinde kesitleroluşturularak daha önceden belirlenmiş görüntüler arasındakibenzerlikler belirlenip çatlak tespiti çalışması yapılmıştır [5]. Evrişimsel Sinir Ağı (ESA) tabanlı çatlak tespit teknikleritemel olarak, çatlak yamalarının tespitine ve üzerlerindesınırlayıcı kutular sağlamaya dayanana blok düzeyindealgılama ve çatlakların piksel düzeyinde algılamasını sağlayançatlak bölümlemesine dayalı piksel düzeyinde algılama olarakikiye ayrılabilir [6-8].

Kaldırım çatlaklarını belirlemede başarıyı artırmak için önce gölge kaldırma yöntemleri kullanan çalışmalar da yapılmıştır. Yöntemlerinde gölgeli kısımların aydınlatması dengelenerek gölge giderme uygulanmıştır [9]. Ancak, bu yöntemlerin imge üzerinde çatlak özelliklerini değiştirdiğinden her imgeye uygulanması mümkün değildir.

Bir diğer çalışma ise imge işleme tekniklerinin en yaygın kullanılan yöntemlerden biri olan eşikleme kullanılmıştır [10]. İmgenin farklı çatlak seviye ve biçimlerine sahip olması durumunda başarıyı azaltacak etkileri olduğu görülmüştür. Bu çalışmada yüzey karmaşıklığını azaltmak için renkli görüntünün gri ölçeğe dönüştürülmesinden sonra medyan filtreleme uygulanmıştır. Ancak, bu çalışmada istenmeyen unsurların ortadan kaldırılması için önerilen teknikler, daha karmaşık ve büyük unsurları ele almak için yetersiz kalmıştır.

Son yıllarda, bazı örüntü tanıma ve görüntü işleme algoritmaları yol çatlaklarını türev kullanarak, filtrelendirmeler yaparak ya da piksel bazında işlemler yaparak tespit etmek için kullanılmıştır. İlk çalışmalarda, birçok araştırmacı yol çatlağı tespitinin doğruluğunu artırmak için fotometrik ve geometrik hipotezlere dayanan eşik [11], kenar algılama [12,13] ve morfoloji [14] ile ilgili yöntemleri benimsemiştir.

Sunulan bu çalışmada araca yerleştirilen kamera vasıtasıyla alınan karayolu görüntülerinden yol çatlaklarını tanımlamak için bir derin öğrenme mimarisi olan VGG-16 kullanılmıştır. Literatürde her yöndeki yüzey çatlaklarını tespit etmek için Gabor Filtreleme[15], yüzey hasarının kalınlık ve derinlik yönünden nicel değerlendirilmesini sağlamak için WEDM işlemi[16] gibi yöntemlere başvurulmuştur. Fakat VGG-16 mimarisinin literatürde sıkça kullanılan LeNet-5 ve AlexNet mimarilerine göre yüksek doğruluk performansı sağladığından ve daha önceden yapılan birçok görüntü işleme uygulamasında gösterdiği başarılardan ötürü özellikle VGG-16 mimarisinin farklı yapıları kullanılmıştır. 


\section{Materyal ve Metot}

Yol anormalisinin tespiti ile ilgili çalışmalar genellikle az sayıda imge ile tek tip sorunların çözümüne odaklanmaktadır. Oluşturulacak sistemin daha tutarlı sonuçlar üretebilmesi için derin öğrenme modelinin eğitiminde gerçek otoyol görüntüleritoplanmış ve 1500 adet görüntü içeren veri seti elde edilmiştir.Doğru ölçüm yapılabilmesi için veri setindeki tüm görüntüler manuel olarak etiketlenmiştir. Kamera aracılı̆̆ıyla gerçek otoyoldan alınan görüntülerin bir kısmı test verisi bir kısmı isedoğrulama verisi olarak ayrılmıştır. Test klasörü ve doğrulamaklasörleri rastgele ayrılmıştır ve içerisinde Şekil 1'de ki gibi çatlak yol görüntüsü ile normal yol görüntüsü içeren dosyaları barındırmaktadır.
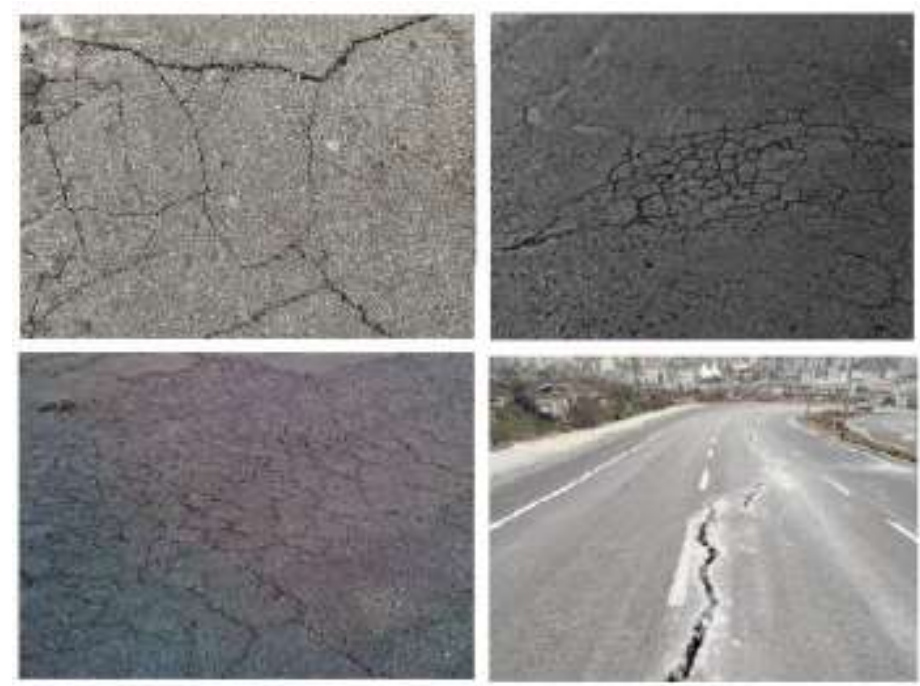

Şekil 1. Gerçek otoyol çatlak görüntüleri

Ayırdığımız verileri öğrenme ve sınıflandırma işlemlerinden geçirdik temel olarak sistemimiz Şekil 2'de resmedildiği gibi ilk olarak orjinal resim olarak sistemde varolmaktadır. Dahasonra resimler Test Veri Seti ve Öğrenme Veri Seti olarak ayırılır. Gerekli model tasarlanarak öğrenme işlemi gerçekleştirilir. Sonra Sınıflandırma işlemi ile resim verileri sınıflara ayrılır. Nihai sonuçta ise modeli test etmek bir resim ile oluşan modelin doğruluğu hesaplanmaktadır.

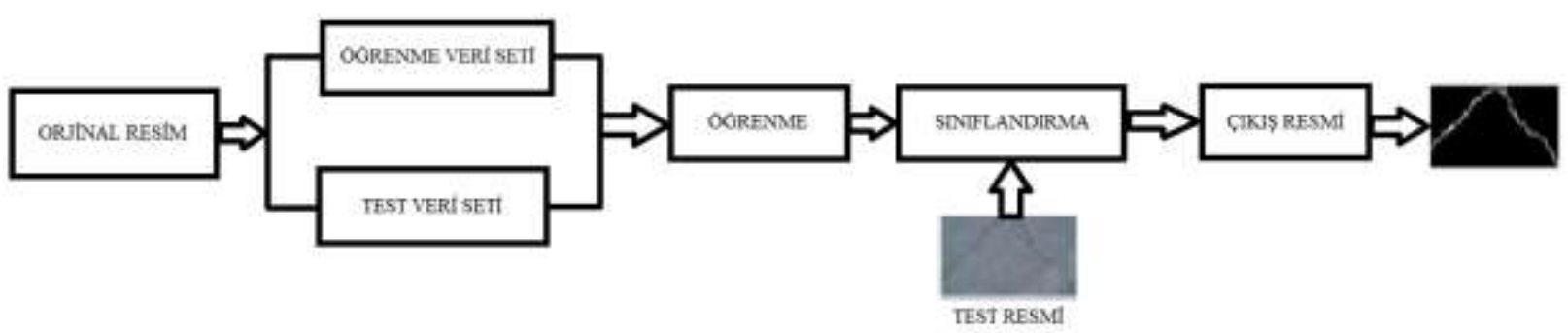

Şekil 2. Sistemin temel adımları

Tüm görüntülerin aynı şekle sahip olması için fotoğrafları modellemeden önce yeniden boyutlandırılması gerekecektir. Bu genellikle küçük kare bir resimdir. Bunu başarmanın birçok yolu vardır, ancak en yaygın olanı her görüntünün en boy oranını esnetip deforme edecek ve onu yeni şekle zorlayacak basit bir yeniden boyutlandırma işlemidir. Daha küçük girdiler, eğitilmesi daha hızlı olan bir model anlamına gelmektedir. Bu yüzden veri setinde bulunan resimleri $224 \times 224$ piksellik sabit bir boyuta yeniden biçimlendirdik. Daha sonra veri setimizde bulunan resimlerin rastgele $\% 25$ 'ini test veri kümesinde geriye kalan \%75'lik bölümü ise doğrulama veri kümesinde olacak şekilde tasarladık.

$\mathrm{Bu}$ çalışmada kullanmış olduğumuz VGG-16 mimarisi, evrişimli katmanların küçük $3 \times 3$ filtrelerle istiflenmesini ve ardından maksimum bir havuzlama katmanını içerir. Bu katmanlar birlikte bir blok oluşturur ve bu bloklar, modelin ilkdört bloğu için 32, 64, 128, 256 gibi ağ derinliği ile her bloktaki filtre sayısının artııldığı yerde tekrarlanır. Çıktı özelliği haritalarının yükseklik ve genişlik 
şekillerinin girdilerle eşleşmesini sağlamak için evrişimli katmanlarda dolgu kullanılır. VGG-16 Mimarisinde; ağın girdisi boyutların görüntüsüdür (224, 224, 3). Şekil 3'de gösterilen ilk iki katman 64 kanala $3 * 3$ filtre boyutuna ve aynı dolguya sahiptir. Daha sonra maksimum havuz adımlarından $(2,2)$ sonra, 256 filtre boyutuna ve filtre boyutuna $(3,3)$ sahip evrişim katmanlarına sahip iki katman bulunur. Bunu, önceki katmanla aynı olan maksimum bir havuzlama adım $(2,2)$ katmanı izler. Daha sonra filtre boyutu $(3,3)$ ve 256 filtre olmak üzere 2 evrişim katmanı vardır. Bundan sonra 2 set 3 evrişim katmanı ve maksimum havuz katmanı vardır. Her biri aynı dolguya sahip $(3,3)$ boyutunda 512 filtreye sahiptir ve bu görüntü daha sonra iki evrişim katmanından oluşan yığına aktarılır [17].

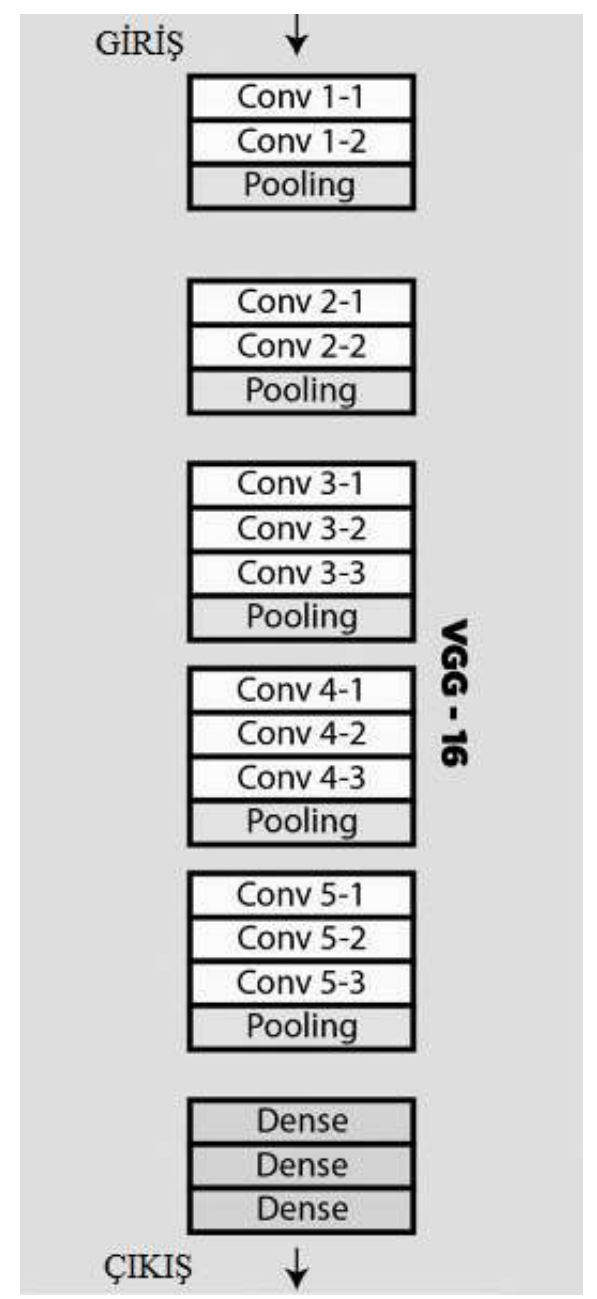

Şekil 3. VGG-16 Mimari Haritası

\section{Bulgular ve Tartışma}

\subsection{Bir Bloklu VGG-16 Modeli}

Tek bloklu VGG-16 modeli, 32 filtreli tek bir evrişimli katmana ve ardından maksimum bir havuz katmanına sahiptir. Bu model 20 adımda öğrenimini tamamlamıştır. Öğrenimini tamamlayan model test veri seti üzerinde \%83,988'lik bir doğruluk elde etmiştir. Şekil 4'deki Çapraz Entropi Kaybı grafiğinde $0,8^{\prime}$ den başlayan kayıp değeri model eğitiminin sonunda 0,6'nın altına inmeyi başarmıştır. Bu durum hem modelin veri seti üzerindeki doğruluğunun artması hem de kayıp değerinin istenilen değer olan 0,1'in altına inmesi için 1 Bloklu VGG-16 çalışmasının yeterli olmadığını göstermiştir. 

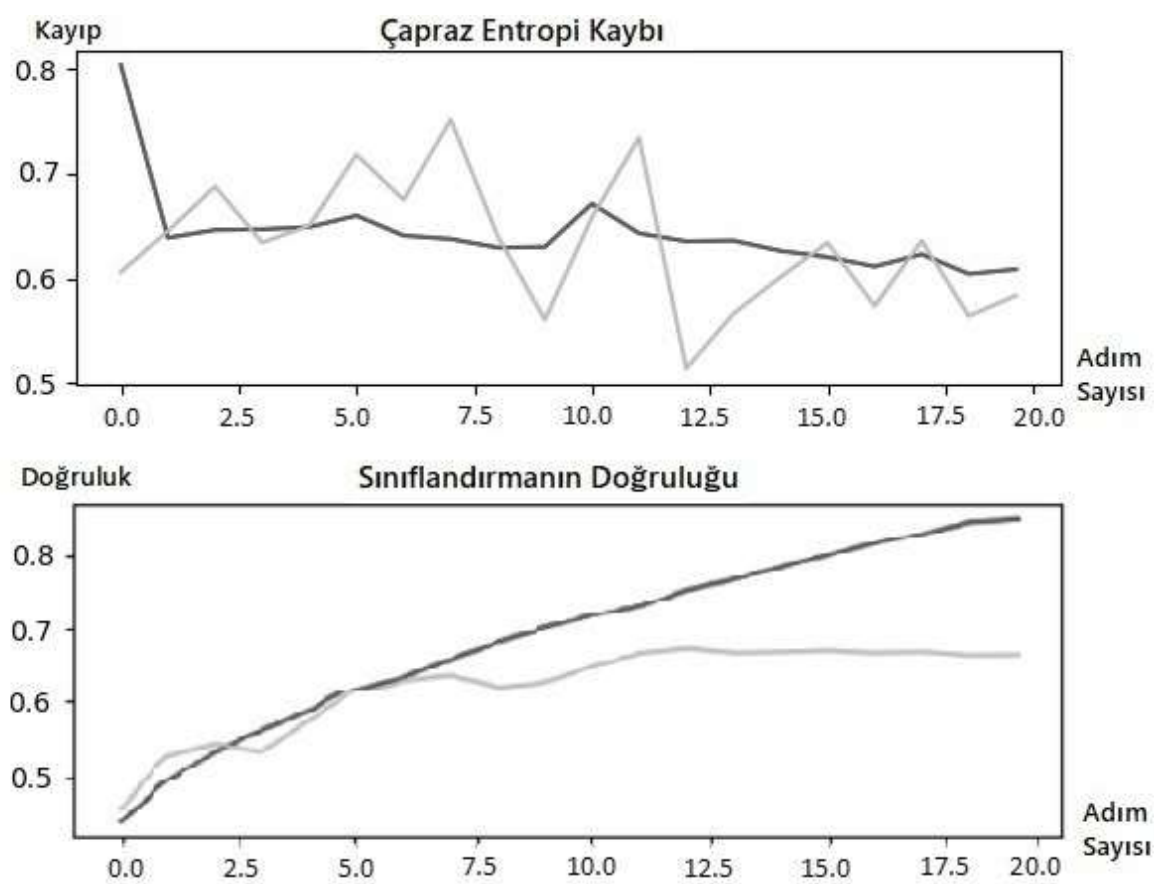

Şekil 4. Çatlaklar ve Normaller Veri Seti’nde Bir Bloklu VGG-16 Modeli içinKayıp ve Doğruluk Öğrenme Modellerinin Çizgi Grafikleri

\section{2. İki Bloklu VGG-16 Modeli}

İki bloklu VGG-16 modeli tek bloklu VGG-16 modelini genişletir ve32 filtreli tek bir evrişimli katmanın yanına 64 filtreli ikinci birblok daha ekler. Model uygun hale getirildi ve testveri setindeki performans raporlandı. Modelin performansının bir bloklu VGG-16' da \% 83,988 iken Şekil 5'te iki bloklu VGG16'da \% 93,895 doğrulukla bir iyileşme elde ettiğini görebiliriz. Öğrenme eğrilerinin grafiğini gözden geçirdiğimizde, modelin eğitim veri setini aştığını görebiliriz. Kayıp değerinin 1 Bloklu VGG-16 'ya nazaran azaldığını ve Doğruluk öğrenme modelinin 1 Bloklu VGG-16’ ya göre arttı̆̆ını görmekteyiz. $\mathrm{Bu}$ muhtemelen modelin artan kapasitesinin bir sonucudur ve bu eğilimin daha iyi olması ve Çapraz Entropi Kayıp değerinin daha da düşmesi gerekmektedir. Bu nedenle veri etimiz 3 Bloklu VGG-16 mimarisine uygulanacaktır.
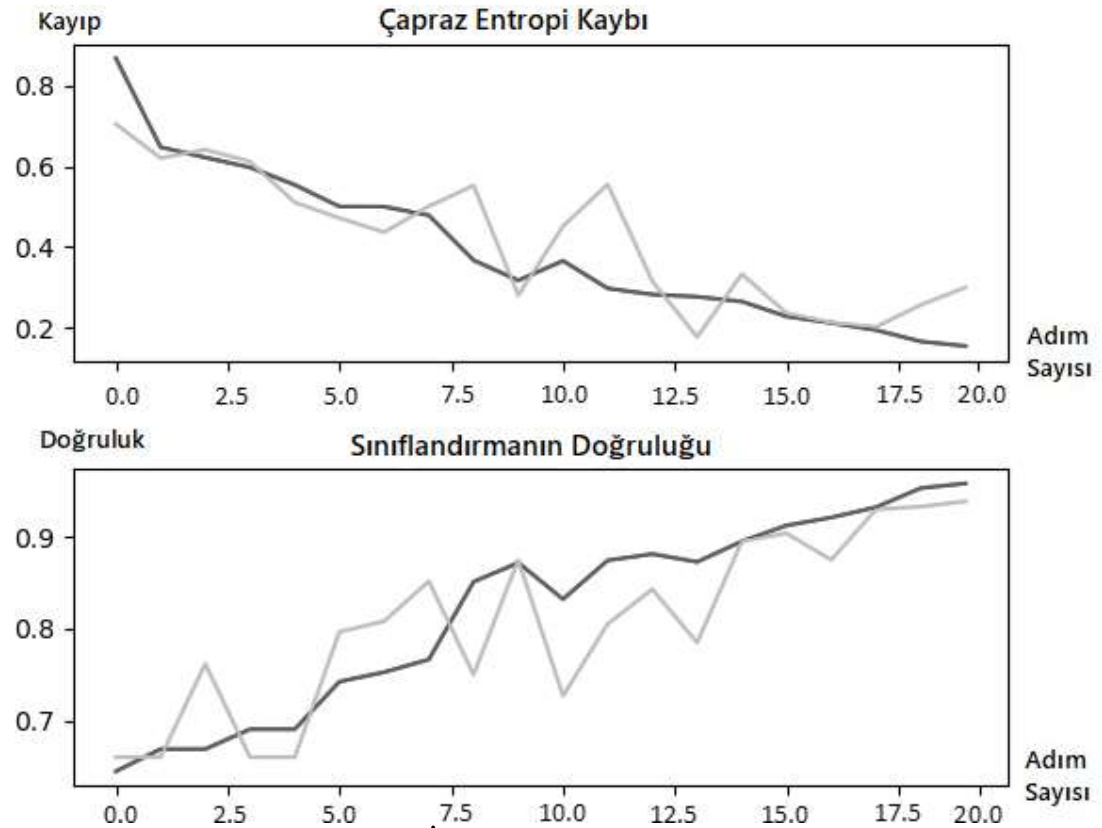

Şekil 5. Çatlaklar ve Normaller Veri Seti’nde İki Bloklu VGG-16 Modeli için Kayıp ve Doğruluk Öğrenme Modellerinin Çizgi Grafikleri 


\section{3. Üç Bloklu VGG-16 Modeli}

Üç bloklu VGG-16 modeli, iki bloklu VGG-16 modelini genişletir ve 128 filtreli üçüncü bir blok ekler. Bu durumda, iki bloklu VGG-16' da \% 93.895 olan doğruluk performansımız, üç bloklu VGG-16'da \% 95.930 hassasiyete kadar artış göstermiştir. Şekil 6'da ki öğrenme eğrilerinin grafiğini gözden geçirdiğimizde, benzer bir aşırı uyum eğilimi görebiliriz. Kayıp değerinin 0,2'nin altına inmesi ve doğruluk değerinin ise yaklaşık olarak \% 96'ya yaklaşması 4 veya 5 Bloklu VGG-16'ya olan ihtiyacı azaltmıştır.
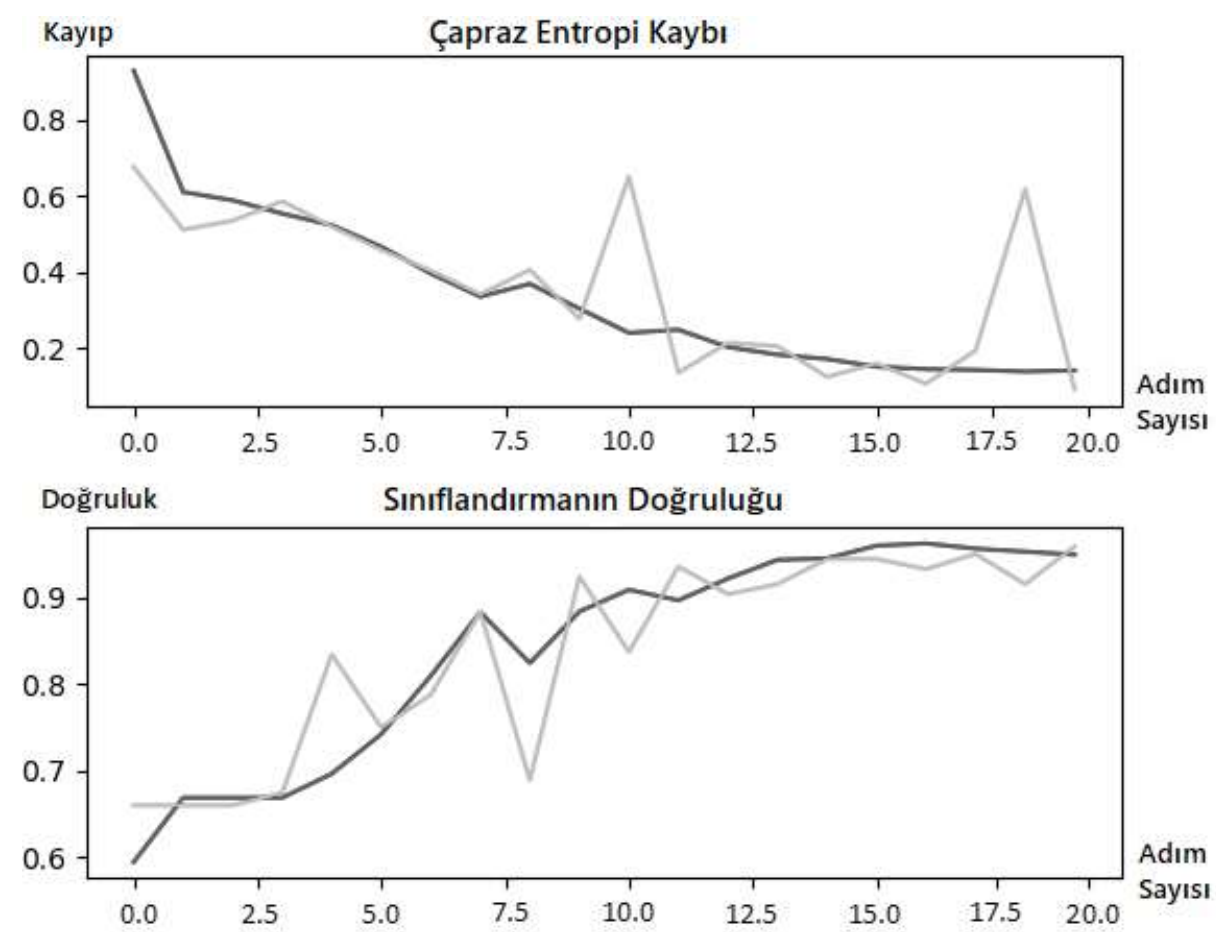

Şekil 6. Çatlaklar ve Normaller Veri Seti'nde Üç Bloklu VGG-16 Modeli için Kayıp ve Doğruluk Öğrenme Modellerinin Çizgi Grafikleri

Tablo 1. 5 kat veri kümesinde farklı eğitilmiş modeller kullanılarak ortalama sınıflandırma başarıları

\begin{tabular}{|c|c|cccccc|}
\hline Model & En Yüksek & \multicolumn{6}{|c|}{ Doğruluk Oran1 } \\
\cline { 5 - 8 } & $\begin{array}{c}\text { Başar1 } \\
\text { Periyot Num. }\end{array}$ & Kat 1 & Kat 3 & Kat 3 & Kat 4 & Kat 5 & Genel \\
\hline AlexNet & 56 & 93.33 & 90.00 & 86.67 & 96.67 & 90.00 & 91.11 \\
LeNet & 64 & 93.33 & 86.67 & 83.33 & 96.67 & 83.33 & 87.50 \\
Vgg-5 & 98 & 83.33 & 86.67 & 76.67 & 93.33 & 76.67 & 83.34 \\
RoICNN & 13 & 96.67 & 93.33 & 90.00 & 100.00 & 96.67 & 95.34 \\
\hline
\end{tabular}

Elde ettiğimiz sonuçları, farklı derin öğrenme modelleri eğitilerek ve farklı adımlarda çalıştırılarak daha önce yapılmış olan Tablo 1'deki çalışmalarla karşılaştırdığımızda modelimizin başarımı ortalama doğruluk oranı en yüksek olan RoICNN modelinden daha iyi olduğunu görmekteyiz [18]. Sonuçlar, modelin muhtemelen düzenleme tekniklerinden yararlanacağını göstermektedir. Bu ağırlık kaybı ve veri büyütme gibi teknikleri olabilir. Ayrıca, eğitim veri setini genişleterek modeli konumlandırmak için daha fazla değişmeyen özellikleri öğrenmeye teşvik ederek performansı da arttrabiliriz.

VGG-16 modeli, belirli bir ImageNet sorgulama veri kümesi üzerinde eğitilmiştir. Bu nedenle, giriş görüntüleri $224 \times 224$ boyutunda yapılandırılır. Bu işlemi Python programlama dilinin h5py kütüphanesinin kullanarak tamamladık. Nihai modelimizi model.h5py adiyla kaydettik. Tahmin etmek için etiketi olmayan bir resim seçerek bu resmi model.h5py isimli nihai modelimizle aynı klasöre kopyaladık. Seçtiğimiz görüntü içerisinde yol çatlağı bulunan bir resimdi. Kaydedilmiş modeli kullanabilmemiz için öncelikle seçtiğimiz resmi 224x224 formatına dönüştürdük ve kodumuzun içine 
dâhil ettik. Model sınıfının predict() metoduna seçmiş olduğumuz içerisinde çatlak bulunan resmi parametre olarak verdik ve sonuçta model çıktısı olarak "1" değerini aldık. Bu değer modelimiz ikili sınıflandırma kullandığından dolayı çatlak var sınıfına ait olduğunu gösterir.

\section{Sonuç ve Öneriler}

$\mathrm{Bu}$ çalışmada yeni bir çatlak tespit yaklaşımı önerilmiştir. Geliştirdiğimiz sistemde araca yerleştirdiğimiz kamera ile karayolunun fotoğraflanması sağlandı. Daha sonra elde edilen fotoğraflar Gray formata ve $224 \times 224$ boyutuna dönüştürüldü. Elimizde bulunan görüntüler daha sonra eğitim ve test adında iki sınıfa, her sınıf içerisinde çatlaklar ve normaller olmak üzere iki sınıfa daha ayrıldı. Bu şekilde, veri önişleme ve ayırma işlemleri tamamlanmış oldu. Daha sonra, 1 Bloklu VGG-16, 2 Bloklu VGG-16 ve 3 Bloklu VGG-16 modelleri kullanılarak sirasiyla \% 83,988, \% 93,895 ve \% 95,930 değerleri elde edilerek ilgili grafikler yardımıyla gösterilmesi sağlandı ve nihai model oluşturuldu. Tahmin için ilgili resim ve kod yapısı oluşturulduktan sonra modelimizin seçtiğimiz resmin çatlak barındırıp barındırmadığını tahmin etmesi sağlandı. Eğitilen model tahmini başarıyla gerçekleştirdi ve doğru sınıfı seçti. Sistemimizin iyileştirilmesi için gelecekteki bir çalışma olarak, pozitif görüntüleri yani çatlakları ve yol yüzeyinden ayırmak için daha fazla resim verisi ile derin bir sinir ağı kullanılarak eğitilebilir.

\section{Yazarların Katkısı}

Yazarlar makaleye eşit oranda katkı sağlamış olduklarını beyan eder.

\section{Çıkar Çatışması Beyanı}

Yazarlar arasında herhangi bir çıkar çatışması bulunmamaktadır.

\section{Araştırma ve Yayın Etiği Beyanı}

Yapılan çalışmada araştırma ve yayın etiğine uyulmuştur.

\section{Kaynaklar}

[1] Koch C., Georgieva K., Kasireddy V., Akinci B., Fieguth P. 2015. A review on computer vision based defect detection and condition assessment of concrete and asphalt civil infrastructure, Advanced Engineering Informatics, 29 (2): 196-210.

[2] Cubero-Fernandez A., Rodriguez-Lozano F.J., Villatoro R. et al. 2017. Efficient pavement crack detection and classification. J Image Video Proc. 2017, 39.

[3] Zakeri H., Nejad F. M., Fahimifar A. 2017. Image based techniques for crack detection, classication and quantication in asphalt pavement: a review, Archives of Computational Methods in Engineering, 24 (4): 935-977.

[4] Tsai Y.-C., Kaul V., Mersereau R. M. 2010. Critical assessment of pavement distress segmentation methods, Journal of Transportation Engineering, 136 (1): 11-19.

[5] Koch C., Brilakis I. 2011. Pothole detection in asphalt pavement images, Advanced Engineering Informatics, 25 (3): 507- 515.

[6] Yang X., Li H., Yu Y., Luo X., Huang T., Yang X. 2018. Automatic Pixel-Level Crack Detection and Measurement Using Fully Convolutional Network.

[7] Futao Ni, Jian Zhang, Zhiqiang Chen,. (2018). Pixel-level crack delineation in images with convolutional feature fusion. Structural Control and Health Monitoring. 26. 10.1002/stc.2286.

[8] Ronneberger O., Fischer P., Brox T. 2015. U-net: Convolutional networks for biomedical image segmentation, International Conference on Medical image computing and computer-assisted intervention, Springer, pp.234-241.

[9] Li P., Wang C., Li S., Feng, B. (2016). Research on crack detection method of airport runway based on twice-threshold segmentation, Proceedings - 5th International Conference on Instrumentation and Measurement, Computer, Communication, and Control, IMCCC 2015, 
$1716-1720$.

[10] Zou Q., Cao Y., Li Q., Mao Q., Wang S. CrackTree: Automatic crack detection from pavement images, Pattern Recognition Letters, (3): 227-238.

[11] Oliveira H., Correia P.L. 24-28 August 2009. Automatic road crack segmentation using entropy and image dynamic thresholding. In Proceedings of the 17th European Signal Processing Conference, Glasgow, Scotland, UK; pp. 622-626.

[12] Zhao H., Qin G., Wang X. 16-18 October 2010. Improvement of canny algorithm based on pavement edge detection. In Proceedings of the 2010 3rd International Congress on Image and Signal Processing, CISP 2010, Yantai, China; Volume 2, pp. 964-967.

[13] Attoh-Okine N., Ayenu-Prah A. 2008. Evaluating pavement cracks with bidimensional empirical mode decomposition. EURASIP J.Adv. Signal Process. 1-7.

[14] Tanaka N., Uematsu K. 17- 19 November 1998. A Crack Detection Method in Road Surface Images Using Morphology. In Proceedings of the Workshop on Machine Vision Applications, Chiba, Japan; 98: 1-4

[15] Medina Roberto, Gayubo Fernando, González Luis M., Olmedo David, Gómez-García-Bermejo Jaime, Zalama Eduardo, Perán José. (2008). Surface Defects Detection on Rolled Steel Strips by Gabor Filters.. VISAPP 2008 - 3rd International Conference on Computer Vision Theory and Applications, Proceedings. 1. 479-485.

[16] Kumar Jatinder, Kumar Anish., 2015. Surface crack density and recast layer thickness analysis in WEDM process through response surface methodology. Machining Science and Technology. Article in Press. 10.1080/10910344.2016.1165835.

[17] Pawangfg. 2020. VGG-16 CNN Model. https://www.geeksforgeeks.org/vgg-16-cnn-model. (Erişim Tarihi: 21.05.2021).

[18] Vedat T, Burhan E. 2019. Intersections and crosswalk detection using deep learning and image processing techniques. Physica A: Statistical Mechanics and its Applications. 543.10.1016/j.physa.2019.123510 